\title{
IMPRENSA NO PARANÁ E O COMBATE AO ANALFABETISMO: TRAJETÓRIA E PENSAMENTO DE RAUL GOMES (1889-1975)
}

\author{
Eliezer Félix de Souza ${ }^{1}$ \\ Névio de Campos ${ }^{2}$
}

\section{RESUMO}

Este artigo tem por objetivo discutir a trajetória de Raul Gomes, particularmente a relação desse intelectual com a imprensa e o movimento contra o analfabetismo. Apóia-se nos conceitos de intelectual e de trajetória, permitindo abordar a condição de jornalista de Raul Gomes e de combatente do analfabetismo no Paraná e Brasil. Assim, enfatiza-se o aspecto mediático desse intelectual paranaense, isto é, a ação de Raul Gomes no processo de formação da opinião pública paranaense. Nesses termos, sustenta-se que a ação pública desse intelectual que resultou na criação de jornais, na produção de textos e na objetivação de uma opinião pública, evidencia o sentido da função do intelectual moderno, nascido no final do século XIX, na França. As intervenções de Raul Gomes na imprensa eram de natureza diversa. Dentre tantas, demos prioridade aos debates sobre a educação, principalmente ao problema do analfabetismo, elemento que ganhou maior relevância no pensamento desse intelectual do Paraná. Com essa discussão sobre a educação, Raul Gomes reafirmava os discursos republicanos que pregavam a crença nas potencialidades humanas, acreditando que elas poderiam ser aperfeiçoadas pelo desenvolvimento da instrução pública.

Palavras-chave: Educação; Imprensa no Paraná; Intelectual; Trajetória.

\section{THE PRESS IN PARANÁ AND THE FIGHT AGAINST ILLITERACY: TRAJECTORY AND THINKING OF RAUL GOMES (1889-1975)}

\begin{abstract}
The aim of this article is to discuss of Raul Gomes's trajectory, particularly the relationship of this intellectual with the press and the movement against illiteracy. It bases itself on the concepts of intellectual and trajectory, approaching the condition of Raul Gomes, the journalist, and fighter against illiteracy in Paraná and Brazil. In this way, the mass media aspect of this intellectual from Paraná is emphasized, that is, Raul Gomes's action in the formation of public opinion in Paraná. In these terms, one sustains that the public action of this intellectual, which resulted in the creation of newspapers and the production of texts, as well as making public opinion more objective, evidences the function of this modern intellectual, born at the end of the $19^{\text {th }}$ century in France. Raul Gomes's interventions in the press were of a diverse nature. Among many, we prioritized the debates on education, especially the problem of literacy, an element which became more important in the thinking of this intellectual from Paraná. With this discussion about education, Raul Gomes reaffirmed the republican speeches which preached the belief in human potentialities, believing that they could be perfected with the development of public education.
\end{abstract}

Keywords: Education. The press in Paraná. Intellectual. Trajectory. 


\section{Introdução}

O objetivo deste texto é discutir alguns aspectos da trajetória de Raul Rodrigues Gomes $^{3}$, privilegiando uma análise de seus ensaios relacionados a educação que foram publicados na imprensa paranaense. Esse percurso analítico apoia-se no conceito de trajetória ${ }^{4}$ de Pierre Bourdieu e em alguns textos jornalísticos dessa personagem.

Nossos primeiros contatos com os escritos jornalísticos de Raul Gomes aconteceram ao acessar o jornal Diário dos Campos, no qual era publicada a coluna "Notas de um repórter". Ele representava, em suas crônicas, uma cidade em plena transformação, criando um efeito de sentido de espanto e utopia, pois tudo parecia grandioso e moderno.

O contato com essas crônicas nos instigou a pesquisar alguns aspectos de sua biografia, quando percebemos que um dos fatos relevantes é que seu nome constava na lista dos signatários do Manifesto dos Pioneiros da Educação Nova, de 1932. Esse episódio foi um indício de que Raul Gomes poderia ser um dos principais articuladores e divulgadores do Manifesto dos Pioneiros na imprensa paranaense. Além disso, observamos que a trajetória desse intelectual paranaense estava marcada pela incursão no jornalismo e defesa de políticas públicas contra o analfabetismo.

Essa aproximação de Raul Gomes com os debates da educação se fez presente desde o início até o final da vida dele. Há um consenso entre os pesquisadores da educação de que, desde o início do século XX, intensificou-se o debate em relação à educação do povo no Brasil. Essas discussões foram promovidas por intelectuais que, além de variada produção bibliográfica, atuavam nos meios da imprensa para a divulgação de seus ideais. Carlos Eduardo Vieira (2007), ao tematizar a imprensa indica que os jornais Diário da Tarde e Gazeta do Povo, fundados em 1899 e 1919, respectivamente, tiveram papel de destaque nas esferas política e social, contribuindo com os debates educacionais ao dar visibilidade aos discursos formativos. Além disso, Vieira observa que o jornal $O$ Estado de São Paulo teve atuação relevante na causa educacional, sobretudo na década de 1920, pois Fernando Azevedo lançou os famosos inquéritos sobre a educação, o que resultou, mais tarde, na publicação do Manifesto dos Pioneiros da Educação Nova.

Com base nessas observações, é possível afirmar que aqueles dois jornais paranaenses atribuíram um sentido fundamental às ideias educativas do período, dando visibilidade ao movimento escolanovista, seguindo indelével a linha editorial do jornal $\mathrm{O}$ Estado de São Paulo. Ao estabelecer um diálogo com aqueles dois jornais da capital do Paraná, observamos que, por um lado, a Gazeta do Povo deu repercussão à necessidade de remodelação da instrução pública paranaense; a urgência da reforma do ensino; e a configuração das Escolas Normais, sem mencionar em nenhum momento o debate promovido pelos escolanovistas; por outro, percebemos que o Manifesto dos Pioneiros da Educação foi publicado integralmente no Diário da Tarde.

A publicação intitulada "Um plano Nacional de Educação" foi feita por partes, ganhando as páginas das edições que circularam entre 29 de março de 1932 e 07 de abril do mesmo ano. Observamos que o Manifesto não sofreu nenhum tipo de análise por parte dos jornalistas, isto é, foi transcrito sem nenhuma discussão que permitisse ao leitor ter uma visão de conjunto em relação ao significado dessa ação do grupo da Escola Nova. Certamente a intenção de Raul Gomes era de apenas dar visibilidade ao documento orquestrado por Fernando de Azevedo, sem a pretensão de criar outros sentidos ${ }^{5}$. Por outro lado, as posições de Raul Gomes eram manifestadas, continuamente, em seus textos que 
tratavam da educação, particularmente da instrução primária e do analfabetismo. A interlocução com esses dois jornais paranaenses permitiu um recorte na trajetória de Raul Gomes, uma vez que ele se destacou na imprensa paranaense, assim como, utilizou-se desses veículos de comunicação para dar visibilidade ao seu pensamento educacional.

Destacamos que "[...] a imprensa, os periódicos, os clubes literários, as igrejas e outros foram espaços utilizados para o culto do moderno e para afirmação modernizadora" (VIEIRA; MARACH, 2007, p. 269). Nas décadas de 1920 e 1930, a causa educacional foi uma bandeira deflagrada pelos intelectuais relacionados à Escola Nova, atuando particularmente a partir da Associação Brasileira de Educação (ABE). Raul Gomes esteve atrelado a esses intelectuais e dentre os paranaenses foi o único nome que apareceu na relação dos que assinaram o Manifesto de 1932. Sua intervenção tanto na imprensa como no campo da educação teve no combate ao analfabetismo sua principal bandeira de luta ${ }^{6}$.

A imprensa começou a ter um papel de destaque na vida social, principalmente no período que marcou a passagem do século XIX para o século XX, pois foi um momento caracterizado pelas transições de pequenas a grandes empresas jornalísticas nos principais centros urbanos brasileiros. Sua atuação passou a traduzir as novas ideias e os hábitos gerados pelas transformações vivenciadas pela população, tornando-se espaço privilegiado para a discussão dos problemas e rumos da sociedade. Em síntese, neste artigo, objetiva-se estabelecer uma discussão da trajetória de Raul Gomes, privilegiando a abordagem da sua ação na imprensa e a promoção do debate educacional nesse lócus de intervenção social.

\section{Raul Gomes, um intelectual da imprensa paranaense}

Raul Gomes, denominado por seus contemporâneos de "príncipe dos jornalistas", proclamava-se "apenas um repórter". Essas adjetivações carregam um tom provocativo. É com esse sentido que decidimos incluir a adjetivação "o príncipe dos jornalistas", atribuída a Raul Gomes pelo jornalista Vasco José Taborda, em artigo escrito e publicado na Revista Rumo Paranaense. Por outro lado, incluímos a denominação, "apenas um repórter", atribuída por Raul Gomes a si mesmo. O leitor pode ficar intrigado para saber qual das duas adjetivaçõos expressa com mais precisão a trajetória de Raul Gomes? Sem dúvida que essa indagação tem certa pertinência. No entanto, para nós tem um sentido menor, pois entendemos que qualquer tentativa de buscar estabelecer uma resposta a esse tipo de questionamento, sempre guardaria um sentido arbitrário.

Se não interessa discutir se Raul Gomes era "o príncipe dos jornalistas" ou "apenas um repórter", o leitor pode ficar mais intrigado e perguntar que motivos têm os autores para destacar esses aspectos no início do artigo? A anotação dessas adjetivações tem a pretensão de destacar que a memória de Raul Gomes é demarcada a partir da imprensa paranaense. Não há dúvida quanto a essa afirmação. Entretanto, a definição do lugar dessa personagem na imprensa paranaense guarda certa ambivalência, pois aos seus colegas Raul Gomes representava a nobreza da imprensa. Mas, na avaliação dele próprio, a sua ação no jornalismo manifestava a atividade artesanal, aquele que recolhe informações, notícias de qualquer natureza.

Raul Gomes era reconhecido pelos agentes da imprensa como um grande jornalista. Essa memória é consagrada pelos seus contemporâneos da imprensa do Paraná. Essa observação indica que Raul Gomes tinha uma rede de amizade e sociabilidade bastante ampla. A sua incursão, seja como participante ou como liderança, em movimentos e projetos culturais pode contribuir para compreender o prestígio que gozava entre os representantes do mundo das letras ${ }^{7}$ do Paraná. 
A trajetória de Raul Gomes foi marcada pela inserção em vários campos, como no magistério, mas particularmente no campo do jornalismo, donde estabeleceu interlocução com instituições culturais e intelectuais da área educacional paranaense e brasileira. Nascido na cidade de Piraquara (hoje grande Curitiba), em 27 de abril de 1889, iniciou seus estudos primários com sua mãe, e em seguida estudou com professores particulares, até que matriculou-se no Ginásio Paranaense e na Escola Normal, onde em 1906, recebeu o diploma de normalista. Na Escola Normal, foi aluno de mestres conhecidos da educação paranaense, como por exemplo, Sebastião Paraná, Dario Vellozo, Emiliano Perneta, Álvaro Jorge e Euzébio da Mota (RUMO Paranaense, ano II, n 24$)$.

No artigo "Função do Mestre: despertar e animar valores", publicado no Diário do Paraná do dia 06 de janeiro de 1970, Raul Gomes refletiu sobre três princípios formadores de sua trajetória: "A administração, o magistério e jornalismo". Dessa trilogia de atuações ele se prende particularmente "em dois de meus [seus] ofícios principais", sendo desses "um vocacional, o da imprensa e outro, me imposto, o professorado de todos os graus". No que se refere ao jornalismo, definia sua missão como se fosse uma intervenção divina: "aprouve Deus me proporcionar ensejo de lançar ou saber e animar vocações". Na sequiência do texto, citando vários exemplos de jornalistas que foram seus alunos, Raul Gomes se define como mestre e formador de outros profissionais ${ }^{8}$.

Por outro lado, na condição de professor ele relaciona vários nomes que foram seus alunos, enfatizando que o "campo que exerci com maior amplitude a capacidade de achar os integrados [...] foi o universitário" (GOMES, 06 jan. 1970). Cita vários nomes que foram seus alunos e conclui dizendo que "desde os primórdios na cadeira de mestre elementar à Universidade tudo fazia para despertar talentos e vocações" (GOMES, 06 jan. 1970).

Raul Gomes era reconhecido entre seus contemporâneos do mundo das letras por ser detentor de diversas virtudes. Um desses capitais era o domínio da escrita. Sobre esse aspecto, o número 24, da Rumo Paranaense, em artigo assinado por Luiz Carlos Tourinho, destaca: "Emiliano foi tão bom professor de português, - e dele, talvez, Raul Gomes tenha ganhado a sua vocação [...]." O domínio da escrita é associado à atividade de jornalista, mas também ao trabalho de professor. O texto de Luiz Carlos Tourinho, publicado na Rumo Paranaense, também ressalta que Raul Gomes "iniciou sua carreira no Magistério na cidade de Morretes, no ano de 1907, depois trabalhou em Rio Negro e Santa Catarina. No ano de 1920 encerrou suas atividades [docentes] na escola elementar."

É interessante observar que no interstício de 1920 a 1940, Raul Gomes não exerceu o magistério. Somente em 1940, ele ingressou no Magistério secundário, permanecendo até 1959, quando se aposentou, já contando com quase 40 anos de trabalho na área da educação primária e secundária. Em 1946, Gomes ingressou no ensino superior, atuando no curso de Direito da Universidade do Paraná. O seu ingresso na Universidade está registrado no Anuário da Universidade do Paraná:

Em outubro de 1947, teve lugar na Faculdade de Direito, o concurso à Docência Livre de "Economia Política" a que se submeteu o único candidato inscrito Bel. Raul Rodrigues Gomes. Tendo sido aprovado nas provas realizadas e de acordo com a aprovação do parecer final da Comissão pelo Conselho Universitário, o candidato foi empossado, recebendo o grau de doutor em Direito. (ANUÁRIO da Universidade, 1946-1947, p. 114). 
Esses dados biográficos indicam que Raul Gomes esteve envolvido com a educação paranaense, pois exerceu o magistério por quase quatro décadas (1907-1920; 1940-1959). Nas memórias escritas por ele próprio, afirmava que na condição de professor primário "pregava reforma, propagando uma escola que, na época se chamava moderna, e por intuição tudo fazia para desenvolver a personalidade da criança" (BIBLIOTECA Pública do Paraná, 1969, p. 19). Na educação secundária levou adiante seu ideal, pois dinamizou seu processo de ensino da língua e da história da pátria, introduzindo debates, pesquisas e monografias. Esse mesmo ideal tentou traduzir, apesar de várias dificuldades, na Faculdade de Direito da Universidade do Paraná.

Segundo Vasco José Taborba, nessa Faculdade promoveu debates, mesas redondas, investigações, entrevistas e o resultado disso tudo foi o surgimento de centros de cultura e debates na capital paranaense. De acordo com José Taborda, nos lugares em que exercitou o magistério, Raul Gomes sempre esteve presente às manifestações cívicas, honrando os nomes tradicionais e os heróis que souberam com arrojo e nobreza unificar o Brasil (RUMO Paranaense, ano II, $\mathrm{n}^{\circ} 24$ ).

Os testemunhos autobiográficos de Raul Gomes reafirmam essa memória marcada por adjetivações positivas:

Durante todos os meus 50 anos de atividade em prol da educação, uma das minhas preocupações consistiu em defender a retribuição condigna ao Magistério de todos os graus. Em todas as campanhas aqui surgidas naquele período, tomei posição a favor dos professores. Houve mesmo momentos em que fui atacado rudemente por membros do próprio magistério que achavam errada minha preocupação e luta por este tema. (BIBLIOTECA Pública do Paraná, 1969, p. 6).

A observação de Raul Gomes indica que sua ação no jornalismo também se caracterizou pela intervenção no campo educativo. Nesse sentido, destacamos o sentido amplo de luta em prol da educação. Ou seja, os cinquenta anos de atividade em prol da educação estão associados a sua atuação no ensino primário (1907-1920), ensino secundário (1940-1959) e ensino superior (1946-1959), mas também a sua intervenção no campo do jornalismo. Não é possível a dissociação entre ação na educação (magistério) e intervenção no jornalismo para compreender a trajetória de Raul Gomes.

Entre os seus contemporâneos, Raul Gomes gozou de grande prestígio. O professor Dário Nogueira dos Santos resumiu a biografia desse intelectual: "Professor, advogado, jornalista, catedrático de Direito, membro fundador do Centro de Letras do Paraná, segundo ocupante da cadeira $\mathrm{n}^{\circ} .34$ da Academia Paranaense de Letras, cujo patrono foi Júlio David Perneta e fundador João David Perneta" (RUMO Paranaense, ano II, $\mathrm{n}^{\circ}$ 24).

No livro "Raul Rodrigues Gomes e seu legado Humanístico" (1977), Valfrido Piloto já na apresentação afirma que:

Por diversos decênios, convivi com aquele lúcido espírito e incansável dinamizador. Integrante de geração muito posterior a sua, sempre fui por ele acolhido como um irmão de lutas, um companheiro cuja presença the era estímulo, e cuja amizade recebida, - e tantas vezes comprovadas de modo especial, - ele redourava e engrandecia, usando no aferimento as exuberâncias do seu coração e todas as complacências do genuíno mestre. (PILOTO, 1977, p. 143). 
No entendimento desse biógrafo, no jornalismo do Paraná, Raul Gomes descerrara sendas até então desconhecidas, agitando campanhas no Diário da Tarde, ao lado de Euclides Bandeira ${ }^{9}$, e, posteriormente, não apenas dirigindo esse jornal, mas colaborando nos principais órgãos de imprensa. No que se refere à educação, Valfrido Piloto (1977, p. 148) comenta que "[...] como inimigo do analfabetismo, ninguém the arrebatou, aqui, a vanguarda, mantendo iniciativas de decisiva importância, como a muita celebrada OPALA $^{10}$, de efeito em todo o Paraná." Ademais, destaca o biógrafo que, no jornalismo, no magistério, na tribuna, nas letras, encontrava sem interrupções, motivos sublimes, e até, por vezes, estardalhastes, para realização do seu pensar.

No jornalismo ingressou cedo, tendo sido correspondente de vários jornais do Paraná, entre eles: Diário dos Campos de Ponta Grossa. Em Curitiba, reviveu a revista humorística do Paraná Olho da Rua. Por longo tempo, foi colaborador do Diário da Tarde, chegando a Redator-chefe. Foi correspondente e colaborador dos jornais Diário de São Paulo e Folha da Manhã (hoje Folha de São Paulo), da cadeia de jornais de Assis Chateaubriand e do Diário de Notícias do Rio de Janeiro, na seção de educação da poetisa Cecília Meireles. Por treze anos foi correspondente de $O$ Globo do Rio de Janeiro. Colaborou ainda nos grandes jornais de Curitiba: O Dia (Redator-chefe), Comércio do Paraná, Folha da Manhã e Gazeta do Povo (RUMO Paranaense, ano II, no 24).

Em razão disso, a Rumo Paranaense, no texto assinado por Vasco José Taborba, o caracterizou como "O Príncipe dos jornalistas":

Raul Rodrigues Gomes, Mestre desassombrado tanto no magistério como no jornalismo, "Príncipe" que era dos jornalistas do Paraná e seus decanos. Incansável lidador, repórter como sempre se disse, por humilde, firme da defesa da liberdade e dos direitos humanos, quer nas direções dos jornais onde predicava a vontade do povo e verberava impiedosamente os seus falsos defensores, fazendo das folhas a estacada da qual luziam as suas palavras de fé nesta Pátria de todos nós. (RUMO Paranaense, ano II, $\left.n^{\circ} 24\right)$. comentários:

Martins Gomes, no texto "Raul Gomes, o Jornalista", teceu os seguintes

Durante mais de sessenta anos acompanhei a vida ativíssima, inteligente e produtiva de Raul Rodrigues Gomes em múltiplas e variadas realizações em prol da educação, da cultura, dos altos sentimentos de humanidade, bem como da valorização da pátria e da terra paranaense. Ele não se limitava ao artigo de fundo, ao editorial. Ia a crítica, a crônica, a notícia, a nota política e a campanha partidária. (RUMO Paranaense, ano II, nº 24).

Em “O adeus do Mestre”, Ali Bark descreveu que Raul Gomes:

[...] foi um grande repórter, aliás, ele se considerava 'apenas um repórter'. Militou na imprensa na época do jornalismo heróico, do periodismo polêmico, de acirradas campanhas e de sanhudas paixões políticas. Democrata puro ${ }^{11}$ e acabado, homem intransigentemente honesto, pôs a sua pena aos serviços dos seus altos ideais. (RUMO Paranaense, ano II, $\left.n^{\circ} 24\right)$.

Segundo Ali Bark, ao lado de Euclides Bandeira e de outros vultos proeminentes da imprensa da época, Raul Gomes escreveu uma página histórica da vida cultural Revista HISTEDBR On-line, Campinas, $n^{\circ}$ 53, p. 133-152, out2013 - ISSN: 1676-2584 
paranaense. Foi, também, ao lado de Euclides Bandeira que Raul Gomes ergueu as primeiras proclamações do Paranismo. Embora ele se considerasse apenas um repórter, Raul Gomes foi muito mais. Foi um sensível escritor, historiador, pesquisador, estudioso incansável.

Ao descrever a trajetória de Raul Gomes Valfrido Piloto comenta:

\begin{abstract}
Seus lances de inato educador, Raul Rodrigues Gomes os transladara, desde 1906, para o jornalismo, principalmente ai um inflexível, um lúcido condutor de gerações, e a sua persistência até os dias presentes, lhe valeria, com inteira propriedade, o título de decano dos jornalistas do Paraná. Pugnou ao lado dos maiores apóstolos regional da pena, e rejeitou por várias vezes, acenos e promessas para ir lutar no cenário nacional, porque estava num rutilante futuro para a terra e o povo paranaenses, o fulcro de suas ambições cívicas. Por estas permaneceu pobre, por estas amargou transes de ingratidão, por estas deixou em cada degrau da subida do Paraná, as marcas de uma obstinação modelar, como homem de pensamento. (RUMO Paranaense, ano II, $\mathrm{n}^{\circ} 24$ ).
\end{abstract}

As biografias e autobiografia de Raul Gomes expressam a tendência de que "certas categorias de escritores sejam propensas a escrever suas memórias e que outras se prestem como objetos de um culto póstumo através de biografias" (MICELI, 2001, p. 83). Em nossa avaliação, a assertiva de Miceli mostra-se pertinente para relativizar as afirmações sobre esse intelectual paranaense, pois "as biografias tratam quase sempre de escritores que se consagraram ainda em vida ou, então, de autores relegados em vida e que são repostos em circulação por conta de estratégias de combate a que recorrem certas igrejas literárias em conjunturas posteriores da vida intelectual” (MICELI, 2001, p. 84).

Não obstante tal relativização, as fontes indicam a profunda relação de Raul Gomes com a imprensa. Ele personificou a luta de um grupo social que elegeu a imprensa como espaço público de intervenção social. Esses debates foram promovidos por intelectuais que, além de variada produção bibliográfica, atuavam na imprensa para a divulgação de seus ideais.

A discussão deste item privilegiou a abordagem da condição de jornalista de Raul Gomes. Dessa forma, enfatizou o aspecto mediático desse intelectual paranaense. Tal abordagem ressalta uma faceta da existência de um intelectual, que ele "existe na e pela mídia. Suas petições, seus manifestos, mesmo suas obras devem passar pelo canal da mídia (imprensa, revistas, TV etc.)" (LECLERC, 2005, p. 88). A outra face do intelectual é a sua produção cultural, filosófica, científica. Em geral, tais condições estão associadas, pois o pertencimento ao campo cultural (artístico, científico, filosófico) é um elemento fundamental para sua inserção no domínio da opinião pública, pois o jornal " [...] entendido como lugar de produção, veiculação e circulação dos discursos - assume uma função importante no processo de formação das representações sobre o mundo" (VIEIRA, 2007, p. 16).

Esta narrativa explorou a dimensão midiática, portanto, a ligação de Raul Gomes com o processo de formação da opinião pública paranaense. Nesse sentido, "o jornal impresso diário é parte de uma estrutura midiática de enorme impacto e cada vez mais, diversificada ação política e cultural" (VIEIRA, 2007, p. 14). Isto é, de acordo com Carlos Eduardo Vieira, "a imprensa permite uma ampla visada da experiência citadina: dos personagens ilustres aos anônimos, do plano público ao privado, do político ao econômico, do cotidiano ao evento, da segurança pública às esferas cultural e educacional” (p. 13). 
Raul Gomes pode ser compreendido como pertencente ao universo dos intelectuais, pois "são eloquentes, fazedores de discursos dos mais variados gêneros. Afinal, são homens do espaço público, no sentido histórico, sociológico e simbólico [...]" (LECLERC, 2005, p. 12).

A condição de um intelectual não se define por uma razão essencialista. A hipótese de Gramsci (2001, p. 18) de que "todos os homens são intelectuais, mas nem todos os homens têm na sociedade a função de intelectuais [...]" é uma fecunda chave de interpretação. É a atividade social de um indivíduo que estabelece a sua condição de intelectual. Dessa forma, é possível sustentar que a ação pública de Raul Gomes que resultou na criação de jornais e na produção de textos e na objetivação de uma opinião pública, evidencia o sentido da função do intelectual moderno, nascido no final do século XIX, na França.

No texto "Os primeiros passos da palavra imprensa", Marco Morel faz algumas interrogações a respeito disso. "Mas afinal, o que significa esta expressão?" (MOREL, 2008, p. 33). Na resposta: "há quem a tome de forma literal como personagem ou agente histórico dotado de vontade, tendência e iniciativa próprias." (p. 33). Para ele, "a expressão opinião pública é polissêmica - também polêmica.” (p. 33).

A chamada opinião pública não é recente no jornalismo e suas principais características datam das duas primeiras décadas do século XVIII na Europa. Carlos Eduardo Vieira argumenta que o conceito de opinião pública está associado à questão da modernidade. Partindo desse princípio, conforme Vieira (2007, p. 19), "a modernidade foi concebida pelos seus principais arautos como a ação edificante da razão que - por meio da ciência, da tecnologia, da instrução e das políticas sociais - universalizaria um novo modo de pensar e agir." Nesse aspecto, os jornais representaram um importante aliado, não só no papel de incentivador de manifestações pedagógicas, como ainda exerceram a importante função de polemização. Por isso, a imagem da imprensa, tanto ontem como hoje, está associada ao seu poder de influenciar a sociedade, de formar a chamada opinião pública ${ }^{12}$.

Em síntese, é possível definir opinião pública como a tentativa de universalização de um novo modo de pensar e agir. A assertiva de Gramsci (2001, p. 209), "todo estrato social tem seu 'senso comum' e seu 'bom senso', que são, no fundo, a concepção da vida e do homem mais difundida" sintetiza a acepção de opinião pública. Para ele (p. 209), "toda corrente filosófica deixa uma sedimentação de 'senso comum': é este o documento de sua efetividade histórica. O senso comum não é algo rígido e imóvel, mas se transforma continuamente, enriquecendo-se com noções científicas e com opiniões filosóficas que penetrarem no costume".

A condição flexível e móvel da opinião pública explica as razões das cruzadas de Raul Gomes na imprensa, pois se tratava de conformar novos modos de pensar e agir, pois ao dialogar com alguns aspectos de sua trajetória transparece a certeza: ele atuou em duas áreas que tinham forte apelo social - educação e jornalismo.

\section{Liquidar o analfabetismo, eis o problema ${ }^{13}$}

No item anterior a preocupação central foi de discutir, a partir de alguns fragmentos, a relação de Raul Gomes com a imprensa, caracterizando-o como um intelectual da imprensa paranaense. A intervenção de Raul Gomes no jornalismo tratava de assuntos de natureza variada, dentre os quais, destacamos suas discussões sobre o problema da educação brasileira. 
Na nota "Um dia para a Educação", publicada no Diário Popular de Curitiba (GOMES, 17 nov. 1966), ele repercutiu sobre o 14 de novembro, uma data criada pelo Governo Federal que foi "dedicada à alfabetização ou desanalfabetização do povo brasileiro". Para ele, "toda a idéia ou toda a iniciativa tendente a cuidarmos do problema número um do Brasil - a educação - me merece e sempre me mereceu simpatias e aplausos irrestritos". Argumentou que, desde "a década inicial do século eu já escrevia em jornais temas ligados a questão". Entretanto, 14 de novembro não deveria ser considerado o dia da alfabetização. Ao contrário, ele definia como marco para o combate do analfabetismo, o dia da Conscrição Escolar.

Esse seria "o dia em que anualmente e com muita solenidade se deveria iniciar o trabalho pela conscrição da classe dos sete anos no ano subseqüente" (GOMES, 17 nov. 1966). Ele criticava que "não basta [va] para atingir o fim essencial de nossas atividades educacionais desencadear periodicamente campanhas pela desanalfabetização de adultos". Por outro lado, defendia que "isso não resolve [resolvia] o problema do Brasil, como não resolveu em país algum do mundo".

Nessas condições defendia que:

A liquidação do analfabetismo ou se fará pela conscrição escolar e pela obrigatoriedade do cumprimento do currículo respectivo ou nunca deixaremos de ser um povo de analfabetos. A fonte para a extirpação dessa leucemia do organismo nacional é o abandono da classe recrutável cada ano e é a dos sete anos, segundo prescrição da Lei de Diretrizes e bases. (GOMES, 17 nov. 1966).

No jornal Indústria e Comércio, datado de 22 e 24/04/1989, em texto escrito por Marisa Ferraro Sampaio, são citadas as palavras de Raul Gomes, nas quais sentencia que estreou nas campanhas contra o analfabetismo em 1907, ao lançar seus artigos no Diário da Tarde, transcritos pela revista $A$ Escola ${ }^{14}$, órgão do professorado paranaense.

No começo do século XX, no afã da República, os relatórios do governo do Paraná indicavam a forte fé no poder profilático da instrução pública. A tônica desses relatórios destacava a significativa atenção do governo na área da instrução pública, muito embora, os relatórios dos inspetores indicassem os limites de recursos, as carências de instalação, a má formação dos professores. No entanto, não localizamos nos relatórios de anos anteriores e posteriores a 1907 dados oficiais que indicassem o índice de crianças fora da escola e de analfabetos no Paraná. Em regra, as observações oficiais tratavam de dimensionar os investimentos do governo na área de instrução pública. Ao tomar contato com as observações do relatório de 1908, podemos afirmar que não havia um censo a respeito do número de crianças de 7 a 14 anos que estavam fora da escola primária no Paraná. Essa indicação pode ser lida na passagem a seguir:

O Regulamento da Instrucção Publica determina que a "Instrucção Primaria é obrigatoria para os meninos de sete a quatorze annos e para as meninas de sete a doze annos" (Art. 22). Para a execução do imperativo regulamentar, manda-se fazer o recenseamento da população infantil [...]. O artigo 22 do Reg., até aqui, tem sido letra morta, porque não se tem levado a effeito os meios de se executar. Não temos recenseamento da população infantil. (PARANÁ, 1908, p. 53). 
As críticas de Raul Gomes são tomadas a partir de dados gerais do Brasil. Mesmo assim, é importante destacar que as intervenções da imprensa, particularmente desse intelectual podem ser interpretadas como discursos de relativização das posições do governo do Paraná. Raul Gomes destacou que sua defesa da escolarização primária ganhou notoriedade ao associar-se ao movimento da Associação Brasileira de Educação.

Nas palavras de Raul Gomes, assim consta sua assertiva:

Bati-me pela escola moderna, depois chamada ativa. [...] Fui delegado do Paraná em três Congressos de Educação: em 1927 em Curitiba, em 1928 em Belo Horizonte e em 1929 em São Paulo. Neles propugnei a adoção da conscrição escolar e obrigatoriedade de um currículo mínimo de quatro anos nas zonas rurais e de seis ou sete anos nas cidades. Nessas grandes assembleias bati-me pela articulação entre o grau primário, o secundário e o superior. Em Belo Horizonte, na seção de encerramento do Congresso, o maior, creio, até hoje realizado no Brasil, falei em nome do Paraná, revelando o trabalho da Gralha Azul, a plantadora de pinheiros e foi essa a primeira vez, que num assembleia notabilíssima se divulgou a obra simbólica mas educadora da já hoje afamada ave da fauna paranaense. (GOMES, 22 e 24 abr. 1989).

A Rumo Paranaense, no artigo intitulado "Dados biográficos do professor Raul Gomes", comenta que, nos anos de 1927, 1928 e 1929, ele representou o Paraná nos Congressos de Educação promovidos pela Associação Brasileira de Educação em Curitiba, Belo Horizonte e São Paulo, tendo proferido várias conferências (RUMO Paranaense, ano II, n 24). Foram nessas conferências que Raul Gomes iniciou uma relação estreita como os principais mentores da educação brasileira das décadas de 1920 e 1930, particularmente com Fernando de Azevedo. No editorial da Rumo Paranaense, no artigo intitulado "A morte de um grande paranaense: Raul Rodrigues Gomes", ele é assim representado: "o jornalista, escritor e pedagogo Raul Rodrigues Gomes, cuja presença na imprensa e em numerosas e decisivas iniciativas culturais de nossa terra, perdurou por várias décadas, se desenvolveu desde o começo deste século até as vésperas da morte daquele intelectual (RUMO Paranaense, ano II, $\mathrm{n}^{\circ} 24$ ).

Com relação aos Congressos da ABE, Bona Junior e Carlos Eduardo Vieira afirmam que:

Os encontros, de abrangência local e nacional respectivamente, inseriram-se no contexto de afirmação da chamada causa educacional, que mobilizou intelectuais de diferentes orientações ideológicas em torno de projetos formativos que pretendiam, nas palavras de Lourenço Filho, originar uma reorganização nacional a partir da organização da cultura. (BONA JUNIOR; VIEIRA, 2007, p. 13).

Bona Junior e Vieira (2007, p. 13) ainda observam que a "atuação dos intelectuais neste período foi decisiva para a configuração do campo educacional brasileiro, a partir de suas iniciativas na definição de políticas publicas para educação, na organização do sistema nacional de ensino, etc. [...]".

O envolvimento nos Congressos da ABE, levou Raul Gomes a participar no Manifesto dos Pioneiros da Educação de 1932. Ele foi signatário da primeira edição do Manifesto dos Educadores em 1932 e do segundo Manifesto dos educadores do Brasil, ambas as edições do professor Fernando de Azevedo da Universidade de São Paulo. 
A relação de Raul Gomes com os integrantes da Escola Nova é testemunhada em vários de seus artigos. Por exemplo, no artigo intitulado "Lourenço Filho: Percursor da Escola Nova", publicado no Diário da Tarde, em 17 de setembro de 1970, Gomes lamentou a morte daquele educador. Na continuação destacou que "consagrou ele a vida inteira, com tempo integral e dedicação exclusiva ao ensino, à criação didática e a difusão dos mais avançados processos psicopedagógicos". Segundo Gomes, Lourenço Filho, Fernando de Azevedo e Anísio Teixeira, estavam na vanguarda, pelejando pela educação.

$\mathrm{Na}$ sequência do texto, Raul Gomes acentuou sua relação com os três representantes do movimento pela escola nova:

\begin{abstract}
Conheci todos os três e muitos outros brasileiros devotados aos ideais da escola nova. E me lhes tornei amigos e admirador incondicional. Com Fernando sinto até hoje o prazer de ter assinado o seu grande e profundo manifesto de 1932, chamado dos pioneiros da educação. Pelo Paraná fui o único distinguido com essa convocação. Subscrevi, sem restrições o segundo de 1942. Lourenço Filho insistiu comigo para escrever livros a Companhia Melhoramentos de São Paulo, como me sucedera relativamente a Fernando de Azevedo quando, inaugurado a brasiliana insistiu para eu publicar qualquer obra num dos setores daquela maravilhosa coleção. Pude entregar meus volumes didáticos para a seção pedagógica e eles circularam por todo o Brasil e me reclamaram novas edições que só lancei há dois anos. (GOMES, 17 set. 1970).
\end{abstract}

Observa-se a filiação de Raul Gomes ao movimento da escola nova. Ele arvoravase de perfilar entre os signatários dos Manifestos de 1932 e 1942. Mais do que isso, esse intelectual paranaense orgulhava-se de ter participado da ação que empreendeu uma série de publicação na Companhia Melhoramentos.

É fundamental destacar a recorrência de personagens históricos atrelarem-se às lideranças intelectuais de maior destaque. Essa observação mostra-se presente nas autorepresentações de Raul Gomes, pois, frequentemente, faz uso dessa estratégia para incluirse no movimento capitaneado por Lourenço Filho, Anísio Teixeira e Fernando de Azevedo. Essa tendência pode ser compreendida a partir da afirmação de Bourdieu: "os detentores do mesmo título tendem a constituir-se em grupo e a dotar de organizações permanentes [...] destinados a assegurar a coesão do grupo [...] e promover os seus interesses materiais e simbólicos" (BOURDIEU, 2002, p. 149).

De todas as discussões educativas que estavam nos horizontes intelectuais, a que ganhou maior relevância no pensamento de Raul Gomes foi o problema do analfabetismo. Essa discussão o acompanhou em diferentes momentos de sua trajetória. No texto, "Os problemas fundamentais do Ensino" (GOMES, 16 dez. 1966), Raul Gomes iniciou dizendo que reduz "a luta contra o analfabetismo a um binômio: conscrição escolar e frequêencia curricular obrigatória das crianças de 07 anos". A seguir expressou que "há quarenta anos, quando este colunista publicava em órgãos importantes desta capital, como a Gazeta do Povo de Acir Plácido e O Dia de Caio Machado e o Diário da Tarde, já combatia a alfabetização rápida como solução do assunto e propugnava a adoção do estágio obrigatório na escola num mínimo de cinco a seis anos. Esse assunto de que retratou Gomes, refere-se ao combate ao analfabetismo.

Entendia que, nos países europeus e Estados Unidos, procuraram o sistema certo, positivo, infalível. E o descobriram. E seu nome é conscrição escolar com obrigatoriedade implacável do currículo previsto, sempre extenso e cada vez mais, na Europa. Na 
avaliação de Raul Gomes, as atitudes desenvolvidas nos países europeus foram imprescindíveis a extinção do analfabetismo. Para isso, ele conclamava que fosse divulgada a campanha "que nenhuma criança de seis anos feitos fique sem escola" (GOMES, 16 dez. 1966). Feito isso, o passo seguinte, seria obrigar aos adeptos da campanha, que permanecessem na escola por todo o período escolar.

Em tom inconformado afirma que

Passaram-se décadas de minha atividade cotidiana pela imprensa em prol da conscrição escolar e da obrigatoriedade da assistência a um currículo decente. As taxas são indecorosas, humilhantes mesmo para um povo tido como civilizado. [...] Um interlúdio de 40 anos entre 1927 e 1966 não foi suficiente para o Ministério da Educação atacar essas questões de base do problema número um do Brasil! Até agora pode se dizer apenas tentativas de executar a conscrição e a obrigatoriedade do currículo de 4 e do de 6 anos. (GOMES, 16 dez. 1966).

No texto "A Luta contra o analfabetismo", publicado no Diário Popular (GOMES, 08 e 09 jan. 1967), centrou-se na falta de ação em relação ao combate ao analfabetismo:

Ora vem se falando desde há meses em planos de trabalho contra o analfabetismo. O Ministério da Educação tem propagado desígnios de combater esse mal energicamente. Mas, e pelo acatamento que me merece iniciativas dessa natureza, conviria ampla publicidade sobre o que se planeja, já se planejou ou se planejará sobre essa guerra sempre oportuna. Não pude até hoje conhecer profundamente esses projetos.

No final do texto, Gomes cobrou "uma profusa disseminação dos projetos do Ministério de Educação". Segundo ele,

Quantos, como eu, com folha corrida de sessenta anos de atividade pelo problema $n^{\circ} .1$ do Brasil, o da educação, sem ter comandado do alto de qualquer posto, mas perpetuamente desejoso de assistir à aplicação de um planejamento eficiente, capaz de nos assegurar que a todo preço, assegurada a sua continuidade, se possa acreditar na possibilidade do encaminhamento da campanha para termo auspicioso. (GOMES, 08 e 09 jan. 1967).

Na mesma direção, no artigo "A Educação e uma publicidade indispensável" (GOMES, 13 jan. 1967), expressou que tem a "[...] impressão que não vem fazendo o Ministério da Educação uma publicidade completa dos planos de reforma do ensino primário e mesmo do secundário." $\mathrm{O}$ que tem chegado, segundo ele, são informações incompletas e obscuras. "Liminarmente impõe-se a quantos se interessam pela educação saber se vige ainda ou não a Lei de Diretrizes e Bases". Ele expressava que parecia "que o Governo da União vai desfechar um ataque frontal e total ao analfabetismo."

Ainda, no dizer dele:

Muitas vezes, por estas colunas já afirmei minha convicção irreversível de que SÓ COM A CONSCRIÇÃO ESCOLAR e aplicação obrigatória da frequência escolar dentro dos currículos legais é possível se atingir, com muito tempo de ação, aquele objetivo, difícil de execução num país 
de 8.500.000 quilômetros quadrados e oitenta milhões de habitantes. (GOMES, 13 jan. 1967).

Para Gomes, com a conscrição escolar sem continuidade "as campanhas intermitentes desencadeadas para o combate ao analfabetismo são inócuas" (GOMES, 13 jan. 1967). Criticou a UNESCO, que com técnicos bem pagos, percorria o mundo todo, com políticas que não acompanhavam o crescimento vegetativo da população.

A Conscrição Escolar seria um projeto de combate ao analfabetismo "que foi o meio pelo qual as nações mais civilizadas puderam acabar com o analfabetismo." (Diário da Tarde, 16 out. 1967). Estabeleceria a ideia, obrigaria a frequência à escola desde os sete anos, com duração mínima de quatro anos para o interior e seis para a cidade. Esse tema foi discutido, também, no artigo "Analfabetismo e educação: sem a conscrição escolar não acabaremos aquele nem desenvolveremos esta" (GOMES, 22 jan. 1970).

No que se refere ao Estado do Paraná, Raul Gomes reporta que a experiência da conscrição escolar foi realizada no Município de Morretes pelo promotor e depois prefeito Sidney Antunes de Oliveira. Oliveira. Na avaliação de Gomes "abraçou o plano de OPALA - em substância constante da conscrição e obrigatoriedade do currículo" (GOMES, 22 jan. 1970). Infelizmente, lamente Gomes, foram apenas tentativas onde nada de objetivo se praticou.

A sua expectativa era que:

No Estado do Paraná, Candido Martins de Oliveira, secretário de Educação e Cultura, já está se antecipando ao próprio MEC e a mim me declarou a possibilidade de o deputado João Calmon, vir assistir à inauguração do educandário ASSIS CHATEAUBRIAND, entrar em contato com aquele titular da pasta executiva da educação para acerto de ação em conjunto. (GOMES, 22 jan. 1970).

Na avaliação de Gomes:

A educação ou a luta contra o analfabetismo - esta fase liminar daquele compreende a conscrição escolar, partindo da escolarização de todos os menores de seis anos feitos, devendo se recrutar quando possível os de idade mais alta até os 13 anos feitos e outro aspecto é o adulto computado em 13 milhões ou mais. Essa faixa etária compreenderá talvez (não possuo dados atualizados no momento) uns.... 9.000.000 de infantes. A coerção mister escolarizar o máximo dessa massa, podendo ser feita na totalidade nas cidades e vilas em marche-marche e sob as penas da lei, sujeitos estão a ela os pais e responsáveis remissos. Podem ser presos e ainda pagar multas. Assim dispõe o código penal em vigor. (GOMES, 22 jan. 1970).

Com um projeto educativo definido, Raul Gomes mesmo assim apresentava-se cético em relação a implantação imediata da conscrição escolar: "julgo duvidoso esse ano possa se aplicar a conscrição escolar por estarmos a menos de um mês da reabertura das aulas" (GOMES, 22 jan. 1970). Reportava-se, como freqüentemente fazia em seus artigos, ao combate do analfabetismo consolidado em países europeus enquanto "o da educação no Brasil permanece nos depreciando e humilhando pela incompetência dos titulares dos órgãos aos quais cabia resolver com a constância e continuidade". 
Raul Gomes afirmava que "[...] o nosso índice de analfabetismo constitui fator de desmoralização do Brasil, mantendo-nos na retaguarda dos povos civilizados" (GOMES, 22 jan. 1970). Para ele, "do ponto de vista nacional, nunca ocorreu um plano sistemático contra esse flagelo inconfessável e aviltante". Entretanto, ele fez alguma ressalva ao Governo Médici:

De 1964, para cá, ocuparam o MEC vários homens. Mas em verdade nada foi feito. No recente Governo Médici passou para a educação um homem de ação e muita experiência administrativa. Deposito fé nele. E esta persistirá se sua Excia. o Ministro Jarbas Passarinho adotar a única providência capaz de erradicar o indecoroso analfabetismo no território brasileiro, A CONSCRIÇÃO ESCOLAR ${ }^{15}$. (GOMES, 22 jan. 1970).

Concluiu o texto com sua máxima: FORA DA CARIDADE NÃO HÁ SALVAÇÃO, AFIRMO E REAFIRMO, E INSISTO, E TEIMO: FORA DA CONSCRIÇÃO ESCOLAR E DO CUMPRIMENTO DO CURRÍCULO LEGAL NUNCA SE EXTINGUIRÁ O ANALFABETISMO E NUNCA O BRASIL PODERÁ EXECUTAR UM PLANO RACIONAL DE EDUCAÇÃO! (GOMES, 22 jan. 1970).

A critica de Raul Gomes a política educacional brasileira se dava, porque no Brasil "não se fala em conscrição escolar e, sim, em desalfabetizar adultos até pelo rádio, o que é possível, mas para combater a nossa pandemia implica em começarmos a construção de nossa casa de moradia ou um arranha-céu pela cuieira ou telhado..." (GOMES, 13 jan. 1969).

Por fim concluiu seu texto dizendo que:

Se Secretário, ou autoridade, substituiria todo aquele faustoso programa a ser estudado pelos 3.000 mestres e administradores municipais pela locução já citada acima. E pedindo até auxilio da polícia e do exército, faria com que o ano de 1970 fosse o ano de inicio de nossa redenção, sendo que em 1973 todos os conscritos teriam cumprido os quatro anos nas escolas dos sertões e vencido a metade nos quadros urbanos. Assevero a meu caríssimo e admirado trabalhador do ensino, da educação e da cultura que se isso não for feito sob ameaça de prisão e outras penas como a multa - nada terá sido feito... Pode essa assertiva desagradar a xeretas e fofoqueiros que se empenhem na ingrata faina da intriga. Não compareço às assembléias planificadas, mais cá de fora escreverei e direi que sem conscrição e currículo obrigatório NUNCA E JAMAIS SE ABOLIRÁ O ANALFABETISMO. (GOMES, 13 jan. 1969).

Concentrados na força da educação, "[...] a falta de instrução do povo foi apontada como uma das causas do descompasso do país em relação ao concerto das nações modernas" (BONA JÚNIOR; VIEIRA, 2007, p. 23). Os mesmos autores mais adiante afirmam que "o índice de analfabetismo figurava como a principal evidência da ignorância do povo e foi incorporada aos discursos políticos e educacionais ao longo do século XX em distintos contextos" (p. 23-24). Apesar de tudo, "os altos índices de analfabetismo não foram apresentados como resultantes da incompetência das elites políticas em promover a educação popular, mas sim pela resistência destas camadas da população em entender os papéis da escola e da educação no desenvolvimento da sociedade brasileira" (p. 24).

Nessas discussões em torno da educação, a escola pública passou a ser reivindicação constante das autoridades do ensino. Carlos Monarcha afirma que "a escola 
aparece como vanguarda da civilização, garantia no futuro de ordem e progresso nacional" (MONARCHA, 1999, p. 42). Essa ufanização com relação à ordem e ao progresso advêm do grande surto de modernização: "instalam-se fábricas, fazem-se prédios bons, abrem-se ruas novas, melhoram-se edifícios públicos, em geral os logradouros da cidade são cuidados; criam-se novos pontos de repouso e embelezamento. Uma febre de progresso rápido, constante e seguro apodera-se dos paulistas" (p. 63). A reforma urbana paulista, por sua vez, traz exigências reformistas das instituições sociais da época: "cadeia, hospício dos alienados, hospitais, polícia urbana e instrução" (p. 69).

Nos discursos republicanos o que predominou efetivamente foi a fé imensurável nas potencialidades humanas que poderiam ser aperfeiçoadas pelo desenvolvimento da instrução pública. A visão da época, em relação à educação, era que a instrução pública representava uma das vias pela qual se efetivariam as aspirações, ao mesmo tempo em que se configuraria numa experiência histórica que se propunha a realizar a felicidade do povo. Segundo Monarcha, "com a proclamação da República, se extravasa a concepção de revolução que relaciona o novo com a idéia de liberdade" (p. 167). Na visão republicana, "pensa-se a educação não como condição de ascensão social, mas como condição prévia para o bom funcionamento das instituições republicanas" (p. 171). Neste sentido, "[...] a instrução popular - a Escola Normal e a instrução primária - é um centro multiplicador das luzes, que colocam as idéias em marcha, impulsionando a história em direção ao progresso e à liberdade" (p. 172).

Após a Proclamação da República, o jornalismo:

[...] se transformaria em imprensa republicana, agente do projeto civilizador, secularmente acalentado. Nela, estamparam-se à exaustão as idéias e imagens do progresso pretendidas pela nova ordem. Ao lado da política, a urbanização foi um de seus grandes temas, veiculada pela festejada modernização do aparelhamento jornalístico, com novas oportunidades tecnológicas para a produção e reprodução do texto e da imagem, em que desdobrou a estética literária parnasiana e moldurada por guirlandas art-nouveaux. Conglomerados jornalísticos consolidaramse naqueles anos eufóricos, introduzindo novas relações no mercado do impresso. O debate político, a veiculação do quadro econômico e a exaltação das transformações urbanas foram conduzidas pela propaganda e pela publicidade, que se profissionalizavam, a serviço de grupos estrangeiros e dos primeiros governos republicanos [...] frase de ordem: $o$ Brasil civiliza-se. (MARTINS; LUCA, 2008, p. 79/80).

Nas primeiras três décadas do século XX, os discursos da imprensa se centraram basicamente numa sociedade que buscava incisivamente o progresso. A imprensa tornouse grande imprensa, otimizada pela conjuntura favorável. Essa transformação apoiou-se basicamente no tão propagado incentivo à alfabetização, à insurgente indústria do papel e ao aparecimento do telefone e telégrafo, que se configuraram como agilizadores do processo de transmissão dos dados que eram elaborados pela redação. A alfabetização, aliás, pedra de toque para os republicanos, somou para a formação do leitor, que encontrou nos periódicos o suporte preferencial para o exercício da leitura e das letras.

As transformações no campo da comunicação impressa seguiram também os contextos social, político e econômico da sociedade brasileira. Essas transformações, sem sombras de dúvida, aconteceram em maior proporção nos grandes centros urbanos brasileiros. Coube à imprensa, neste período, um importante papel na veiculação de representações aceitas pela sociedade em geral. 
Diante dessa afirmação podemos enfatizar que Raul Gomes não apenas pensou, escreveu e teve atuação de influência do desenvolvimento cultural e educacional do Estado do Paraná. Em seus discursos ele combateu o analfabetismo e teve a sua trajetória integrada as principais discussões educacionais de sua época - seu desejo era ver uma nação alfabetizada e isso ele acreditava que era a consequência para uma sociedade melhor.

\section{Considerações finais}

O objetivo deste artigo foi analisar a trajetória do professor e jornalista Raul Gomes, privilegiando a sua atuação na imprensa e a posição de combate ao analfabetismo. Desse modo, a partir de alguns fragmentos escritos sobre esse intelectual, assim como de seus próprios artigos jornalísticos, procuramos discutir a hipótese de que ele pode ser definido como intelectual da imprensa.

Raul Gomes teve posição reconhecida no campo do jornalismo. Nessa atividade ingressou muito cedo, tendo sido correspondente de vários jornais do Paraná, entre eles com destaque para o jornal Diário da Tarde, além de jornais de outros estados. Na imprensa paranaense promoveu campanhas, tendo como principal foco de discussão o combate ao analfabetismo. Essa foi uma bandeira que carregou no jornalismo, no magistério, nas letras e em todos os documentos onde registrou seu pensamento.

Do interior da educação e imprensa, Raul Gomes iniciou sua intensa interlocução com intelectuais brasileiros. Ao participar de congressos, academias e meios culturais, ele estabeleceu relação estreita com os principais mentores da educação brasileira das décadas de 1920 e 1930, particularmente, com Fernando de Azevedo, vindo a assinar o Manifesto dos Pioneiros da Educação.

Destacamos a relação de Raul Gomes com a imprensa e o intenso combate ao analfabetismo. Ao observar a intervenção de Raul Gomes na imprensa, é possível afirmar que os jornais paranaenses atribuíram um sentido fundamental às ideias educativas do período, dando visibilidade ao movimento escolanovista, seguindo a linha editorial do jornal O Estado de São Paulo. Ao cotejar os números da Gazeta do Povo e do Diário da Tarde do período de 1930 e 1934 (tempo intermediário do Manifesto de 1932), percebemos que a Gazeta do Povo, repercutiu a necessidade de remodelação da instrução pública paranaense; a urgência da reforma do ensino; e a configuração das Escolas Normais. No entanto, não mencionou em nenhum momento, o debate promovido pelos escolanovistas. Por outro lado, no Diário da Tarde, observamos que o Manifesto dos Pioneiros da Educação foi publicado na íntegra.

$\mathrm{Na}$ década de 1920, a causa educacional foi uma bandeira deflagrada pelos intelectuais relacionados a Escola Nova e em seu entorno se formou um grupo de intelectuais influentes na sociedade brasileira. Raul Gomes esteve atrelado a esses intelectuais e no Estado do Paraná foi o único nome que apareceu na relação dos que assinaram o Manifesto de 1932. Apesar de não ampliar o debate em relação ao movimento renovador, no espaço do jornal, a intervenção dele foi significativa, pois a sua trajetória teve inserção em vários campos da cultura paranaense.

Portanto, é possível destacar que Raul Gomes incorporou o sentido moderno de intelectual, ao entender que caberia aos letrados a responsabilidade de discutir os problemas da sociedade e indicar os caminhos para sua superação. Ele fez-se na imprensa, 
foi um intelectual da imprensa. E nos espaços da imprensa promoveu debates sobre a educação brasileira, destacando-se suas discussões de combate ao analfabetismo.

\section{Fontes:}

BIBLIOTECA PÚBLICA DO PARANÁ. Raul Rodrigues Gomes, 1889-1975. Curitiba, 1969, p. 19.

GOMES, Raul. Os problemas fundamentais do ensino. Diário Popular. Curitiba, 16 dez. 1966.

GOMES, Raul. Decano dos mestres paranaense recebe medalha: Fundepar. Diário da Tarde. Curitiba, 16 out. 1967.

GOMES, Raul. Analfabetismo: as terapêuticas para acabá-lo. Diário do Paraná. Curitiba, 13 nov. 1969.

GOMES, Raul. Lourenço Filho: Precursor da Escola Nova. Diário da Tarde. Curitiba, 17 set. 1970.

GOMES, Raul. Liquidar o analfabetismo: eis o problema. Diário do Paraná. Curitiba, 09 out. 1970 .

GOMES, Raul. Sem liberdade impossível: educação, instrução e cultura. Diário do Paraná. Curitiba, 25 abr. 1970.

GOMES, Raul. A Luta contra o analfabetismo. Diário Popular. Curitiba, 08 e 09 jan. 1967.

GOMES, Raul. A Educação e uma publicidade indispensável. Diário Popular. Curitiba, 13 jan. 1967.

INDÚSTRIA E COMÉRCIO. Raul Rodrigues Gomes (1889-1989): o centenário do "Príncipe dos Jornalistas Paranaenses", Curitiba, 22 e 24 abr. 1989.

REVISTA Rumo Paranaense. Curitiba, ano II, $\mathrm{n}^{\circ} 24$.

ANALFABETISMO e educação: sem a conscrição escolar não acabaremos aquele nem desenvolveremos esta. Tribuna do Paraná. Curitiba, 22 jan. 1970.

PILOTO, V. Raul Rodrigues Gomes e seu legado Humanístico. In: Separata do Boletim do Instituto Histórico, Geográfico e etnográfico paranaense. Curitiba, vol. 32, 1977.

\section{Referências}

ANDRADE, M. L. de. Dario Vellozo e a escola moderna: a renovação do pensamento educacional no Paraná (1906-1918), In: VIEIRA, Carlos Eduardo (Org.). Intelectuais, educação e modernidade no Paraná (1886-1964). Curitiba: Ed. UFPR, 2007, p. 191-215. BOURDIEU, P. Razões Práticas: sobre a teoria da ação. Campinas: Papirus, 1996.

O poder simbólico. Rio de Janeiro: Bertrand Brasil, 2002.

BONA JÚNIOR, A.; VIEIRA, Carlos Eduardo. O discurso da modernidade nas conferências educacionais na década de 1920 no Paraná. In: VIEIRA, Carlos Eduardo (org.). Intelectuais, educação e modernidade no Paraná (1886-1964). Curitiba: Ed. UFPR, 2007, p. 13-40. 
BURKE, P; BRIGGS, A. Uma história social da mídia: de Gutenberg à internet. Rio de janeiro: Zahar, 2006.

CARVALHO, M. M. C. Molde nacional e fôrma cívica (1924-1931). Bragança Paulista: Edusf, 1998.

GRAMSCI, A. Cadernos do cárcere. v. 2. Rio de Janeiro: Civilização Brasileira, 2001.

HABERMAS, J. Mudança estrutural da esfera pública: investigações quanto a uma categoria da sociedade burguesa. Rio de Janeiro: Tempo Brasileiro, 1984.

LECLERC, G. Sociologia dos intelectuais. São Leopoldo: Unisinos, 2005.

LUCA, T. R. História dos, nos e por meio dos periódicos. In: PINSKY, C. B. (Org.). Fontes Históricas. São Paulo: Contexto, 2005. p. 111-153.

MARACH, C. B. Inquietações modernas: discurso educacional e civilizacional no periódico a escola (1906-1910). 2007. Dissertação (Programa de Pós-Graduação em Educação) - Universidade Federal do Paraná, Curitiba, 2007.

MARCHETE, T. D. Corvos nos galhos das acácias: o movimento anticlerical em Curitiba (1896-1912). Curitiba: Aos Quatro Ventos, 1999.

MARTINS, A. L.; LUCA, T. R. (Orgs.). História da imprensa no Brasil. São Paulo: Contexto 2008.

MICELI, S. Intelectuais à brasileira. São Paulo: Companhia das Letras, 2001.

MONARCHA, C. Escola normal da praça: o lado noturno das luzes. Campinas, SP: Ed. Da Unicamp, 1999.

MOREL, M. Os primeiros passos da palavra impressa. In: MARTINS, A. L.; LUCA, T. R. (Org.) História da imprensa no Brasil. São Paulo: Contexto 2008.

OSINSKI, D. R.B. Entre o sacerdócio e o ofício: Raul Gomes e o papel do professor (1914-1928). In: CAMPOS, N. de; SUASNABAR, C. (Orgs.). Educação no Brasil e na Argentina: escritos de história intelectual. Ponta Grossa: UEPG, 2013, p. 7-31.

OSINSKI, D. R. B. Missão e não profissão: o papel do professor na concepção de Raul Rodrigues Gomes (1914-1928). In: CONGRESSO BRASILEIRO DE HISTÓRIA DA EDUCAÇÃO, 6, 2011, Vitória. Anais... Vitória: EDUFES, 2011. p. 1-15.

OSINSKI, D. R. B.; BRANDALISE, A. C. "Malhadas e remalhadas": Raul Gomes e o uso da imprensa em prol da educação e da cultura (1920-1970). In: CONGRESSO BRASILEIRO DE HISTÓRIA DA EDUCAÇÃO, 7, 2013, Cuiabá. Anais... Cuiabá: EDUFMG, 2013. p. 1-13.

PAGNI, P. A. Do manifesto de 1932 à construção de um saber pedagógico. Ijuí: Unijui, 2000.

PARANÁ, Inspetor Geral da Instrução Pública. Relatório do inspetor geral da instrução pública do Estado do Paraná Arthur Pedreira de Cerqueira apresentado ao Secretário de Interior, Justiça e Instrução Pública Coronel Luiz Antonio Xavier em 31 de dezembro de 1908. Curytiba, 1909.

SOUZA, E. F. de. Intelectuais, modernidade e discurso educativo no jornal "Diário dos Campos" (1907-1928). 2010. Dissertação (Mestrado em Educação) - Universidade Estadual de Ponta Grossa, Ponta Grossa, 2010. 
VIEIRA, C. E. Jornal diário como fonte e como tema para a pesquisa em história da Educação: um estudo da relação entre imprensa, intelectuais e modernidade nos anos de 1920. In: OLIVEIRA, Marcus Taborba de. (Org.). Cinco estudos em história e historiografia da Educação. $1^{a}$ ed., Belo Horizonte: Autêntica Editora, 2007, v. 1, p. 1140 .

VIEIRA, C. E. O movimento pela escola nova no Paraná trajetória e ideias educativas de Erasmo Pilotto, Educar em Revista. Curitiba, nº 18, p. 53-73, 2001.

VIEIRA, C. E.; MARACH, C. B. Escola de mestre único e escola serena: realidade e idealidade no pensamento de Erasmo Pilotto. In: VIEIRA, C. E. (Org.). Intelectuais, educação e modernidade no Paraná (1886-1964). Curitiba: UFPR, 2007, p. 269-291.

\section{Notas:}

${ }^{1}$ Doutorando em Educação no Programa de Pós-Graduação em Educação da Universidade Estadual de Ponta Grossa (UEPG). Email: eliezer.felix@ hotmai.com.

${ }^{2}$ Doutor em Educação. Professor no Programa de Pós-Graduação em Educação e Programa de Mestrado em História da UEPG. Email: ndoutorado@ yahoo.com.br.

${ }^{3}$ Doravante Raul Gomes.

${ }^{4} \mathrm{O}$ conceito de trajetória diferencia-se do entendimento comum de biografia. Os eventos biográficos não seguem uma linearidade progressiva e de causalidade, linearidade de sobrevoo que ligue e dê sentido a todos os acontecimentos narrados por uma pessoa. Do ponto de vista de Bourdieu, é impossível dar sentido a um todo que escapa ao próprio sujeito histórico, determinado socialmente, imerso em um universo social fora de nossos controles. No seu entendimento podemos acompanhar as mudanças sucessivas pelas quais um agente social passa durante seu movimento na sociedade e que acabam por sedimentar um habitus relacionado à história do indivíduo. Compreender os personagens em uma abordagem diferente das biografias comuns, a partir do conceito de trajetória, contribui para "descrever a série de posições sucessivamente ocupadas pelo mesmo escritor em estados sucessivos do campo literário [...]" (BOURDIEU, 1996, p. 71). Em suma, a vantagem dessa proposta metodológica é que os agentes sociais pesquisados podem ser estudados em processo, durante o desenrolar de suas histórias de vida, após alguma mudança significativa em seu grupo social.

${ }^{5}$ Lembramos que a transcrição do texto da manifestação da educação não foi acompanhada de apresentação do responsável pela publicação. Entretanto, é fato que Raul Gomes era integrante do corpo jornalístico daquele período, e como ele estava envolvido com os signatários do manifesto, pressupõe que foi o responsável pela publicação.

${ }^{6}$ Na Biblioteca Pública do Paraná, um conjunto de obras, recortes de jornal, jornais arquivados em microfilmes testemunham a ação que essa personagem, por muito tempo, exerceu no Estado do Paraná.

${ }^{7}$ A expressão mundo das letras é utilizada para sintetizar os diferentes espaços sociais e culturais do Paraná.

${ }^{8}$ Observemos a autodenominação "apenas um repórter" tinha um caráter muito mais retórico, pois sua trajetória esteve envolvida com inúmeros projetos culturais do Paraná. Parecer ser mais recorrente a representação de que ele assumiu a identidade de liderança no campo do jornalismo paranaense.

${ }^{9}$ Consultar a obra Corvos nos galhos das acácias: o movimento anticlerical em Curitiba (1896-1912) de Tatiana Dantas Marchete que trata de Euclides Bandeira.

${ }^{10}$ Operação Paraná de Liquidação do Analfabetismo.

${ }^{11}$ Em vários de seus textos jornalísticos que trataram do problema do analfabetismo, Raul Gomes elogiou programas de alfabetização dos governos militares que buscavam. Não é objeto de discussão deste texto, porém essa relação entre Raul Gomes e regime militar poderá ensejar novas pesquisas. 
12 Segundo Peter Burke e Asa Briggs (2006, p. 78), "genericamente, os jornais contribuíram para o aparecimento da opinião pública, termo que tem seu primeiro registro em francês por volta de 1750 , em inglês em 1781; e em alemão, em 1793". Jürgen Habermas também aborda a questão da opinião pública a partir da automização da esfera pública. Segundo o autor, o jornal dos tempos modernos, principalmente a partir do século XVIII seguiu engajado nas lutas em prol da afirmação dos valores burgueses. Com relação à opinião pública, Habermas entende que o sujeito é o público enquanto portador de opinião pública. Nesse aspecto, os jornais tiveram papel fundamental, pois "passaram de meras instituições publicadoras de notícias para, além disso, serem porta-vozes e condutoras da opinião pública, meios de luta da política partidária" (HABERMAS, 1984, p. 214).

${ }^{13}$ Artigo publicado no jornal Diário do Paraná, 09/10/1970.

14 A Revista Escola foi objeto de investigação na dissertação de Caroline Baron Marach. Além disso, mencionamos a pesquisa em andamento de Claudia Zanlonrenzi, desenvolvida no Programa de PósGraduação em Educação da Universidade Estadual de Ponta Grossa.

${ }^{15}$ As passagens que, aparecem no texto, em caixa alta. Decidimos manter a forma original.

Recebido em setembro-13

Aprovado em novembro-13 